\title{
PENGARUH NILAI PELANGGAN TERHADAP KEPUASAN PELANGGAN MENGGUNAKAN SPRING BED MEREK COMFORTA DI KOTA PALU
}

\author{
PUTRI DWI AVRIANI \\ ROSIDA P. ADAM \\ FARID \\ Jurusan Manajemen, Fakultas Ekonomi, Universitas Tadulako \\ Email: pdwiavriani@gmail.com
}

\begin{abstract}
This research aims to know the effect of customer value while simultan and partially on customer satisfaction by using spring bed of Comforta In the Palu City. The independent variables used in this research are Functional Value (X1), Value For Money (X2), Social Value (X3), and Emotional Value $(X 4)$. While the dependent variable is Satisfaction (Y). The research method used in this research is descriptive causal. Sampling technique using Insidential sampling with the samples of 100 respondents. The method analysis using multiple linear regression. The results indicate that simultaneously customer value consisting of functional value (X1), value for money (X2), social value (X3) and emotional value (X4) have significant effect to customer satisfaction by using Spring Bed of Comforta in Palu City. The Partially customer value consisting of functional value (X1), value for money (X2), and emotional value (X4) have significant effect to customer satisfaction by using spring bed of Comforta in Palu City. While variable social value (X3) partially have no significant effect on customer satisfaction by using spring bed of Comforta in Palu City.
\end{abstract}

Keywords: Customer Value, Satisfaction.

\begin{abstract}
ABSTRAK
Tujuan dari penelitian ini yaitu untuk mengetahui pengaruh nilai pelanggan baik secara simultan maupun parsial terhadap kepuasan pelanggan menggunakan spring bed Comforta Di Kota Palu. Variabel independen yang digunakan dalam penelitian ini adalah Nilai Fungsional (X1), Nilai Biaya/Value For Money (X2), Nilai Sosial (X3), dan Nilai Emosional (X4). Sedangkan variabel dependen adalah Kepuasan Menggunakan (Y). Metode penelitian yang digunakan dalam penelitian ini adalah deskriptif kausal. Sampel yang digunakan pada penelitian ini yaitu sebanyak 100 responden dengan bentuk pengambilan sampel menggunakan teknik Insidential sampling. Metode analisis data yang digunakan dalam penelitian ini adalah metode analisis regresi linear berganda. Hasil penelitian ini menunjukkan bahwa secara simultan nilai pelanggan yang terdiri dari nilai fungsional (X1), nilai biaya/value for money (X2), nilai sosial(X3) dan nilai emosional (X4) berpengaruh signifikan terhadap kepuasan pelanggan menggunakan spring bed Comforta di Kota Palu. Secara parsial nilai pelanggan yang terdiri dari nilai fungsional (X1), nilai biaya/ value for money (X2), dan nilai emosional (X4) berpengaruh signifikan terhadap kepuasan pelanggan menggunakan spring bed merek Comforta di Kota Palu. Sedangkan variabel nilai sosial (X3) secara parsial berpengaruh tidak signifikan terhadap kepuasan pelanggan menggunakan spring bed Comforta di Kota Palu.
\end{abstract}

Kata Kunci: Nilai Pelanggan, Kepuasan.

\section{PENDAHULUAN}

Tidur merupakan salah satu kebutuhan manusia yang paling mendasar. Tanpa tidur yang cukup dan berkualitas, manusia akan mengalami gangguan kesehatan atau bahkan juga bisa mendapat gangguan mental. Hal tersebut dikarenakan pada saat tidur, tubuh manusia mengalami pemulihan dan pengembangan secara fisik maupun mental. Kasur pegas/spring bed adalah sebuah kasur yang dibuat menggunakan kombinasi per dan busa, tidur menggunakan kasur ini dinilai lebih nyaman. Industri spring bed saat ini telah menjadi salah satu bisnis yang cukup pesat pertumbuhannya. Hal ini dapat 
dilihat dari banyaknya industri spring bed seperti Olimpyc Group dengan produk spring bed Merek Procella, PT. Cahaya Buana Intitama dengan produk spring bed merek Bigland, dan Massindo Group dengan produk spring bed merek Spring Air, Therapedic, Comforta, Super Fit, dan Protect-A-Bed.

Berdasarkan hasil pra penelitian yang dilakukan penulis pada 30 responden/pelanggan tentang kepuasan mereka setelah membeli dan menggunakan spring bed Comforta. Menurut pelanggan spring bed Comforta merupakan produk yang juga mampu memberikan nilai dari segi emosional dan sosial untuk para penggunanya. Proses pra penelitian tersebut memberikan informasi berupa tanggapan positif dari pelanggan pengguna spring bed Comforta bahwa spring bed Comforta merupakan kasur yang nyaman digunakan saat tidur, tidak membuat kepanasan, memiliki sandaran yang kuat dan empuk, mudah dibersihkan, merupakan merek spring bed yang trend dan cukup berkelas di kalangan mereka, memiliki desain yang menarik sehingga sangat cocok dengan interior kamar tidur, serta mendapatkannya sangat mudah.

\section{Tujuan Penelitian Ini Adalah:}

1. Untuk mengetahui pengaruh nilai pelanggan yang terdiri dari nilai fungsional, nilai biaya/Value for money, nilai sosial, dan nilai emosional terhadap kepuasan pelanggan menggunakan spring bed merek Comforta di Kota Palu.

2. Untuk mengetahui pengaruh nilai fungsional terhadap kepuasan pelanggan menggunakan spring bed merek Comforta di Kota Palu.

3. Untuk mengetahui pengaruh nilai biaya/value for money terhadap kepuasan pelanggan menggunakan spring bed merek Comforta di Kota Palu.

4. Untuk mengetahui pengaruh nilai sosial terhadap kepuasan pelanggan menggunakan spring bed merek Comforta di Kota Palu.

5. Untuk mengetahui pengaruh nilai emosional terhadap kepuasan pelanggan menggunakan spring bed merek Comforta di Kota Palu.

\section{KAJIAN LITERATURE}

\section{Pengertian Nilai Pelanggan}

Nilai pelanggan adalah selisih antara evaluasi calon pelanggan atas semua manfaat serta semua biaya tawaran tertentu dan alternatif-alternatif lain yang dipikirkan. Nilai yang dipikirkan pelanggan didasaran pada perbedaan antara apa yang didapatkan pelanggan dan apa yang diberikannya untuk berbagai kemungkinan pilihan. Pelanggan mendapatkan manfaat dan mengandaikan biaya. Pemasar dapat meningkatkan nilai tawaran pelanggan dengan kombinasi menaikkan manfaat fungsional atau emosional dan/atau mengurangi satu atau lebih berbagai jenis biaya (Kotler \& Keller, 2016:173).

Menurut Tjiptono (2015:118) secara sederhana nilai pelanggan mengacu pada perbedaan antara manfaat yang didapatkan konsumen melalui akses atau kepemilikan dan pemakaian sebuah produk atau jasa, dan biaya yang dikeluarkan untuk memperoleh manfaat tersebut.

\section{Dimensi Nilai Pelanggan}

Menurut Sweeney dan Soutar dalam Tjiptono (2006:298) terdapat beberapa dimensi persepsi nilai pelanggan yaitu

1. Nilai Fungsional (Kualitas/Kinerja) yaitu utilitas yang didapatan dari produk karena reduksi biaya jangka pendek dan biaya jangka panjang.

2. Nilai biaya/value for money adalah utilitas yang diperoleh dari persepsi terhadap kualitas dan kinerja yang diharapkan atas produk.

3. Nilai sosial sebagai nilai suatu barang atau jasa yang di rasakan oleh konsumen karena kemampuan barang/jasa tersebut dalam meningkatkan konsep diri-sosial konsumen.

4. Nilai Emosional adalah utilitas yang berasal dari perasaan atau efektif/emosi positif yang ditimbulkan dari mengonsumsi suatu produk. 


\section{Pengertian Kepuasan Pelanggan}

Kepuasan pelanggan dapat diartikan sebagai perbandingan antara harapan atau ekspektasi sebelum pembelian dan persepsi terhadap kinerja setelah pembelian. Apabila persepsi tersebut lebih besar atau minimum sama dengan ekspektasi sebelum pembelian, maka ia puas. Bila tidak, maka yang terjadi adalah ketidakpuasan (Tjiptono, 2015:76).

\section{Kerangka Pemikiran}

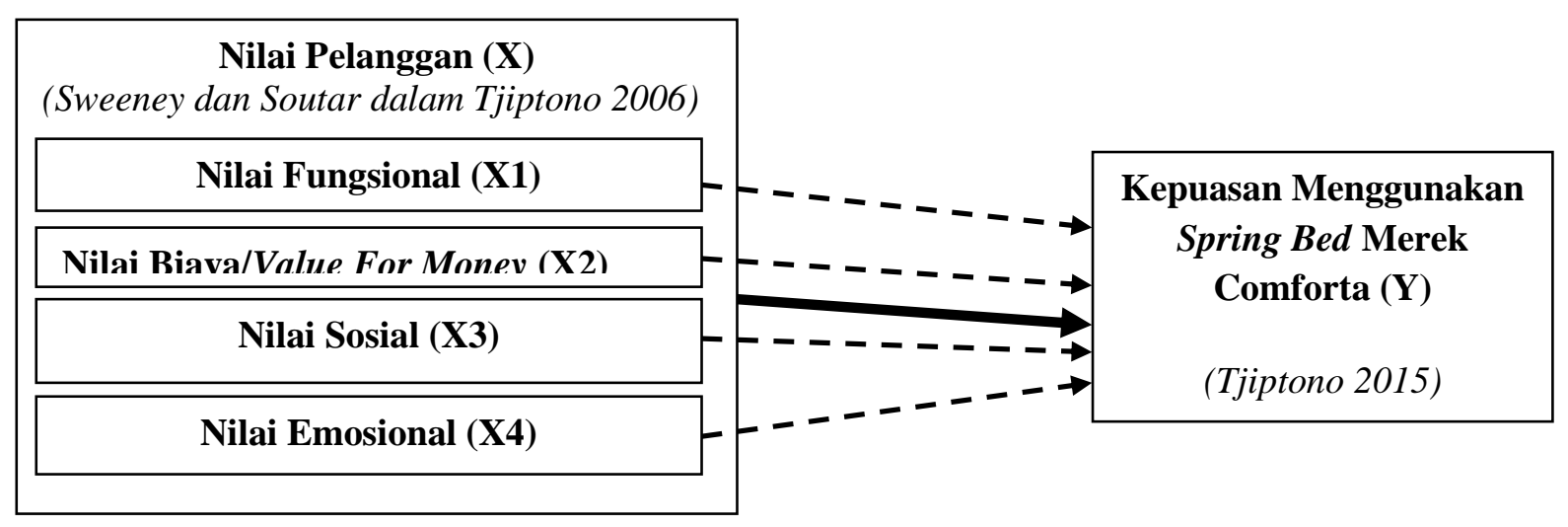

\section{Gambar 1. \\ Kerangka Pemikiran Penelitian}

\section{Keterangan:}

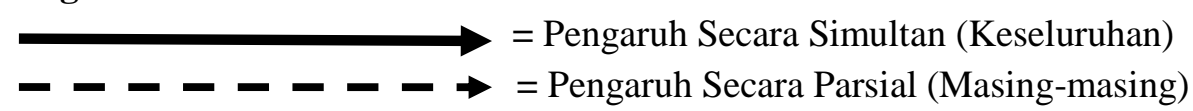

Adapun hipotesis dalam penelitian ini sebagai berikut:

1. Nilai pelanggan yang terdiri dari nilai fungsional, nilai biaya/value for money, nilai sosial, dan nilai emosional berpengaruh signifikan terhadap kepuasan pelanggan menggunakan spring bed merek Comforta di Kota Palu.

2. Nilai fungsional berpengaruh signifikan terhadap kepuasan pelanggan menggunakan spring bed merek Comforta di Kota Palu.

3. Nilai biaya/ value for money berpengaruh signifikan terhadap kepuasan pelanggan menggunakan spring bed merek Comforta di Kota Palu.

4. Nilai sosial berpengaruh signifikan terhadap kepuasan pelanggan menggunakan spring bed merek Comforta di Kota Palu.

5. Nilai emosional berpengaruh signifikan terhadap kepuasan pelanggan menggunakan spring bed merek Comforta di Kota Palu.

\section{METODE PENELITIAN}

Jenis penelitian adalah deskriptif dengan obyek yang diteliti bersifat sebab akibat (kausal) yang terdiri dari variabel independen yaitu nilai pelanggan dan variabel dependen yaitu kepuasan. Sehingga peneliti dapat menemukan pengaruh antara nilai pelanggan terhadap kepuasan pelanggan menggunakan produk spring bed merek Comforta di Kota Palu. Teknik pengumpulan data dengan pengamatan, wawancara, dan membagikan kuesioner serta hasil penelitian cenderung untuk di generalisasikan.

Populasi dalam penelitian ini adalah seluruh pelanggan yang menggunakan produk spring bed merek Comforta di Kota Palu. Adapun jumlah populasi dalam penelitian ini tidak dapat diketahui secara pasti, karena tidak memiliki data yang pasti mengenai para pelanggan yang membeli produk spring bed merek Comforta di Kota Palu. Teknik penarikan sampel dilakukan secara Insidental Sampling yaitu teknik penentuan sampel berdasarkan kebetulan, yaitu siapa saja yang secara 
kebetulan/insidental bertemu dengan peneliti dapat digunakan sebagai sampel, bila dipandang orang yang kebetulan ditemui itu cocok sebagai sumber data. (Sugiyono, 2014:122).

Jumlah sampel pada penelitian ini merujuk pada teori Roscoe dalam Sugiyono (2014:130) adalah minimal 10 kali dari jumlah variabel yang diteliti (variabel independen + variabel dependen). Jumlah variabel dalam penelitian ini adalah 5 yang terdiri dari variabel independen (nilai fungsional, nilai biaya/value for money, nilai sosial, dan nilai emosional) dan variabel dependen (kepuasan pelanggan). Berdasarkan pertimbangan tersebut maka peneliti menetapkan jumlah sampel sebesar 20 x 5 variabel yaitu 100 responden. Penelitian ini menggunakan aplikasi software SPSS (Statistical Program For Social Scane) versi 19.0. yang dipakai untuk menganalisis pengaruh secara simultan dan pengaruh secara parsial variabel nilai pelanggan terhadap kepuasan pelanggan.

Penelitian ini menggunakan teknik analisis linear berganda. Menurut Sugiyono (2014:277) bahwa model umum bentuk persamaan alat analisis statistik parametrik regresi linear berganda dapat digambarkan sebagai berikut:

$$
Y=a+b 1 X 1+b 2 \times 2+b 3 \times 3+b 4 X 4
$$

Dimana:

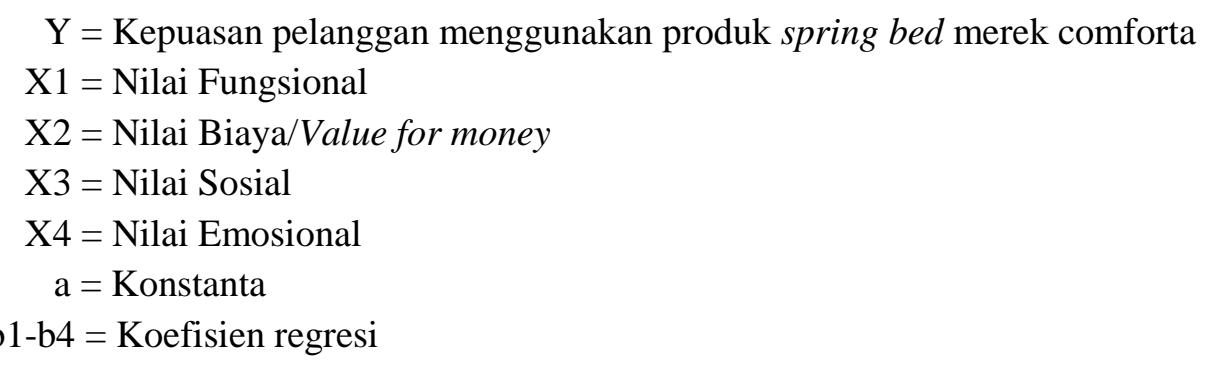

\section{HASIL DAN PEMBAHASAN}

Analisis Regresi Linear Berganda

Tabel 1

Rekapitulasi Analisis Regresi Linear Berganda

\begin{tabular}{|l|c|c|c|c|c|}
\hline \multicolumn{5}{|c|}{ Dependen Variabel Y = Kepuasan Menggunakan } \\
\hline Variabel Independen & $\begin{array}{c}\text { Unstandardized } \\
\text { Coefficients }\end{array}$ & $\begin{array}{c}\text { Standardized } \\
\text { Coefficients }\end{array}$ & $\mathbf{T}$ & Sig \\
\cline { 2 - 6 } & $\mathbf{B}$ & $\begin{array}{c}\text { Standar } \\
\text { Error }\end{array}$ & Beta & & \\
\hline $\mathrm{C}=$ Costanta & .684 & .362 & & 1.888 & .062 \\
\hline Nilai Fungsional $\left(\mathrm{X}_{1}\right)$ & .251 & .065 & .266 & 3.870 & .000 \\
\hline $\begin{array}{l}\text { Nilai Biaya/ Value For } \\
\text { Money }\left(\mathrm{X}_{2}\right)\end{array}$ & .144 & .039 & .260 & 3.687 & .000 \\
\hline Nilai Sosial $\left(\mathrm{X}_{3}\right)$ & .029 & .072 & .024 & .399 & .691 \\
\hline Nilai Emosional $\left(\mathrm{X}_{4}\right)$ & .494 & .077 & .502 & 6.391 & .000 \\
\hline $\begin{array}{l}\text { Multiple } \mathrm{R}=0.817 \\
\mathrm{R} \text { Square }\left(\mathrm{R}^{2}\right)=0.667\end{array}$ & \multicolumn{5}{l}{ Sig.F $=0.000$} \\
\hline
\end{tabular}

Berdasarkan hasil tersebut apabila ditulis dalam bentuk standardized dari persamaan regresinya adalah sebagai berikut:

$$
Y=0.684+0.251 X_{1}+0.144 X_{2}+0.029 X_{3}+0.494 X_{4}
$$




\section{Pembahasan Atas Hasil Analisis}

\section{Pengaruh Nilai Fungsional $\left(\mathrm{X}_{1}\right)$ Terhadap Kepuasan Pelanggan}

Berdasarkan hasil pengujian serta analisis yang telah dilakukan pada penelitian membuktikan bahwa nilai fungsional berpengaruh signifikan terhadap kepuasan konsumen menggunakan spring bed merek Comforta di Kota Palu. Hasil ini menunjukkan bahwa suatu produk yang melaksanakan fungsinya dengan baik akan menimbulkan penilaian yang positif dari pelanggan yang secara otomatis akan mempengaruhi kepuasan mereka.

\section{Pengaruh Nilai Biaya/Value For Money $\left(\mathrm{X}_{2}\right)$ Terhadap Kepuasan Pelanggan}

Berdasarkan hasil pengujian serta analisis yang telah dilakukan pada penelitian membuktikan bahwa nilai biaya/value for money berpengaruh signifikan terhadap kepuasan pelanggan menggunakan spring bed merek Comforta di Kota Palu. Pada dimensi nilai biaya/value for money, kepuasan pelanggan tercipta karena pelanggan menilai bahwa spring bed Comforta memiliki harga yang masuk akal sesuai dengan manfaat dan keunggulan yang dimiliki produknya yang semuanya tercermin dalam biaya-biaya yang dikeluarkan untuk mendapatkannya. Hasil ini menunjukkan bahwa pelanggan dalam membelanjakan uangnya atau mengeluarkan biaya-biaya akan mempertimbangkan kualitas produk serta manfaat apa yang akan didapatkannya sebagai pertukaran pengorbanan uang/biaya-biaya yang digunakan untuk mendapatkannya.

\section{Pengaruh Nilai Sosial $\left(\mathrm{X}_{3}\right)$ Terhadap Kepuasan Pelanggan}

Berdasarkan hasil pengujian serta analisis yang telah dilakukan pada penelitian membuktikan bahwa nilai sosial berpengaruh tidak signifikan terhadap kepuasan pelanggan menggunakan spring bed merek Comforta di Kota Palu. Hal ini dikarenakan menurut responden yang menjadi sampel dalam penelitian ini, spring bed merupakan suatu barang yang tidak selalu bisa dibawa kemana-mana, tempat untuk menyimpannya pun di ruangan-ruangan khusus sehingga tidak terlihat langsung oleh banyak orang, kecuali dalam waktu-waktu tertentu. Hal ini menyebabkan nilai sosial berpengaruh tidak signifikan terhadap kepuasan pelanggan menggunakan spring bed merek Comforta di Kota Palu.

\section{Pengaruh Nilai Emosional $\left(\mathbf{X}_{4}\right)$ Terhadap Kepuasan Pelanggan}

Berdasarkan hasil pengujian serta analisis yang telah dilakukan pada penelitian membuktikan bahwa nilai emosional berpengaruh signifikan terhadap kepuasan konsumen menggunakan spring bed merek Comforta di Kota Palu. Hasil tersebut menunjukkan bahwa manfaat yang dirasakan para pengguna spring bed Comforta dari hasil pengalaman mereka menggunakan produk, mampu menciptakan emosi dan perasaan yang tepat bagi pelanggan. Spring bed Comforta merupakan spring bed yang sangat empuk sehingga tidak menimbulkan rasa sakit saat berlama-lama duduk ataupun berbaring serta tidak membuat kepanasan saat tidur.

\section{KESIMPULAN DAN SARAN}

\section{Kesimpulan}

1. Koefisien regresi dimensi nilai fungsional $\left(\mathrm{X}_{1}\right)$ sebesar 0.251 , artinya jika nilai fungsional meningkat maka kepuasan konsumen menggunakan spring bed merek Comforta di Kota Palu akan meningkat dan sebaliknya.

2. Koefisien regresi dimensi nilai biaya/value for money $\left(\mathrm{X}_{2}\right)$ sebesar 0.144 , artinya jika nilai biaya meningkat maka kepuasan konsumen menggunakan spring bed merek Comforta di Kota Palu akan meningkat dan sebaliknya.

3. Koefisien regresi nilai sosial $\left(\mathrm{X}_{3}\right)$ sebesar 0.029 , artinya jika nilai sosial meningkat maka kepuasan konsumen menggunakan spring bed merek Comforta di Kota Palu akan meningkat dan sebaliknya. 
4. Koefisien regresi dimensi nilai emosional $\left(\mathrm{X}_{4}\right)$ sebesar 0.494 , artinya jika nilai emosional meningkat maka kepuasan konsumen menggunakan spring bed merek Comforta di Kota Palu akan meningkat dan sebaliknya.

\section{Saran}

1. Pada nilai fungsional diharapkan perusahaan memberikan perhatian lebih pada standar kualitas dalam pembuatan spring bed Comforta diantaranya pada pegas yang digunakan dan pada kain spring bed yang digunakan agar tidak mudah sobek.

2. Pada nilai biaya/value for money, diharapkan pihak perusahaan agar terus melakukan inovasi terhadap produk spring bed Comforta terutama pada desain atau tampilan fisik dari produk lebih diberikan sentuhan keunikan dan motif-motif atau corak-corak warnah yang lebih bervariasi lagi sehingga pelanggan semakin tertarik dan tidak mudah bosan.

3. Pada nilai sosial, diharapkan pihak perusahaan agar senantiasa meningkatkan kualitas produk spring bed Comforta dan juga terus meningkatkan citra merek dari produk sehingga mudah dikenali oleh pelanggan maupun masyrakat pada umumnya.

4. Pada dimensi nilai emosional, diharapkan pihak perusahaan terus melakukan inovasi pada produk spring bed Comforta seperti dilengkapi fleep free, Orthopedic, dan keunggulan lainnya yang bisa membuat pelanggan akan selalu merasa senang menggunakannya.

5. Peneliti selanjutnya sebaiknya menggunakan sampel yang lebih banyak lagi, menggunakan metode penelitian yang berbeda, dan melakukan penelitian di lokasi yang berbeda agar dapat tercipta generalisasi hasil penelitian.

\section{REFERENSI}

Kotler, Philip \& Keller, Kevin Lane. (2016). Manajemen Pemasaran. Edisi 12. Jilid I. Jakarta: Indeks.

Sugiyono. (2014). Metode Penelitian Kuantitatif Kualitatif dan R\&D. Bandung: Alfabeta.

Sugiyono. (2014). Metode Penelitian Bisnis. Bandung: Alfabeta.

Tjiptono, Fandy. (2006). Pemasaran Jasa. Malang: Bayumedia.

Tjiptono, Fandy. (2015). Strategi Pemasaran. Edisi 4.Yogyakarta: Andi. 